\title{
Hypothesis: Kisspeptin Mediates Male Hypogonadism in Obesity and Type 2 Diabetes
}

\author{
Jyothis T. George ${ }^{a}$ Robert P. Millar ${ }^{a, c}$ Richard A. Anderson ${ }^{a, b}$ \\ ${ }^{a}$ Medical Research Council, Human Reproductive Sciences Unit, and bivision of Reproduction and Developmental \\ Sciences, University of Edinburgh, Centre for Reproductive Biology, The Queen's Medical Research Institute, \\ Edinburgh, UK; ${ }^{C}$ Receptor Biology Group, Division of Medical Biochemistry, University of Cape Town, Cape Town, \\ South Africa
}

\section{Key Words}

Kisspeptin $\cdot$ Obesity $\cdot$ Metabolism $\cdot$ KISS1 $\cdot$ KISS1R .

GPR-54 - Diabetes - Metabolic syndrome - Hypogonadism •

Testosterone

\begin{abstract}
Hypogonadism occurs commonly in men with type 2 diabetes (T2DM) and severe obesity. Current evidence points to a decreased secretion of gonadotropin-releasing hormone (GnRH) from the hypothalamus and thereby decreased secretion of gonadotropins from the pituitary gland as a central feature of the pathophysiology in these men. Hyperglycaemia, inflammation, leptin and oestrogen-related feedback have been proposed to make aetiological contributions to the hypogonadotropic hypogonadism of T2DM. However, the neuroendocrine signals that link these factors with modulation of $\mathrm{GnRH}$ neurons have yet to be identified. Kisspeptins play a central role in the modulation of GnRH secretion and, thus, downstream regulation of gonadotropins and testosterone secretion in men. Inactivating mutations of the kisspeptin receptor have been shown to cause hypogonadotropic hypogonadism in man, whilst an activating mutation is associated with precocious puberty. Data from studies in experimental animals link kisspeptin expression with individual factors known to regulate $\mathrm{GnRH}$ secretion, including hyperglycaemia, inflammation, leptin and oestrogen. We
\end{abstract}

therefore hypothesise that decreased endogenous kisspeptin secretion is the common central pathway that links metabolic and endocrine factors in the pathology of testosterone deficiency seen in men with obesity and T2DM. We propose that the kisspeptin system plays a central role in integrating a range of metabolic inputs, thus constituting the link between energy status with the hypothalamic-pituitarygonadal axis, and put forward potential clinical studies to test the hypothesis.

Copyright $\odot 2010$ S. Karger AG, Basel

\section{Introduction}

Over the past few decades, obesity has become a global health challenge. Between 1980 and 2004 the prevalence of obesity increased from 15 to $33 \%$ in the United States - a pattern mirrored across the world [1]. Interlinked with this, the number of people with type 2 diabetes (T2DM) has also risen, and is predicted to rise further [2]. There is also an emerging consensus that T2DM and obesity are part of the same disease spectrum such that the term 'metabolic syndrome' is used to describe these overlapping pathophysiological processes [3].

Whilst the cardiovascular effects of T2DM and obesity have been extensively studied, the impact on fertility and hypogonadism remains relatively under-explored. 
Low testosterone concentrations in men have been shown to be associated with obesity and T2DM [4]. Plasma-free testosterone, total testosterone and sex hormone-binding globulin are low in obesity and recover in proportion to the degree of weight loss [5]. In men with established T2DM, decreased plasma-free testosterone is found in a third to half of all patients [6].

The relationship between hypogonadism and metabolic status, consistently seen across race and ethnic groups [7], also seems to be bidirectional. In obese men, biochemical hypogonadism (low testosterone) increases the risk of future development of diabetes [8]. In hypogonadal individuals with T2DM, treatment with testosterone improves the glucose and lipid profile [9], and enhances quality of life and cardiac performance [10].

The pathophysiology of low plasma testosterone in men with T2DM as well as the broader neuroendocrine signalling processes by which the metabolic milieu influences reproduction remains poorly understood [11]. However, the recent discovery of kisspeptin and its cognate receptor GPR-54 (KISS1R) as modulators of GnRH and, thus, downstream secretion of gonadotropins and testosterone [12] may help solve at least a part of this complex jigsaw.

Here we review human and animal experimental data on the potential role for kisspeptin in mediating metabolic inputs that modulate the hypothalamic-pituitarygonadal (HPG) axis and put forward propositions for clinical studies to test this central role for kisspeptin as an integrator of metabolic cues with reproductive function in men with metabolic syndrome.

\section{Hypothesis}

We hypothesise that decreased endogenous kisspeptin secretion plays a central role in mediating hypogonadotropic hypogonadism in men with obesity and T2DM.

\section{Hypogonadism in Obesity and Diabetes}

A number of possible pathologies have been proposed as causative factors for hypogonadism in individuals with obesity and/or T2DM. Metabolic factors (hyperglycaemia, inflammation, oxidative stress) and testicular factors (decreased Leydig cell function) have all been proposed as factors contributing to the hypogonadal state in these individuals [4]. However, current evidence points to a decreased secretion of gonadotropin-releasing hormone $(\mathrm{GnRH})$ from the hypothalamus as the key factor [4], as evidenced by the low or relatively low luteinising hormone (LH) and follicle-stimulating hormone (FSH) concentrations in the large majority of these men with low plasma testosterone. LH pulse amplitude and secretory masses are significantly lower in obese men than in lean controls [13]. Moreover, there is a highly significant negative correlation between plasma-free testosterone and body mass [13]. A normal LH and FSH response to $\mathrm{GnRH}$ has also been demonstrated in obese individuals, suggesting a hypothalamic rather than a pituitary defect. [14].

\section{The Role of Kisspeptin in GnRH Secretion}

Kisspeptins are peptide products of the KISS1 gene [15]. Various forms of kisspeptin have been identified, all of which have the same decapeptide amino acid sequence at the C-terminus [12]. Kisspeptins regulate the reproductive axis by stimulation of their cognate receptor KISSIR (also called GPR-54) on GnRH neurons, thereby regulating $\mathrm{LH}$ and FSH secretion [12]. Administration of kisspeptin has been shown to increase plasma LH, FSH and testosterone in a dose-dependent manner in a number of species including man [16], and a central role of kisspeptin in the metabolic regulation of reproductive function is well-recognised [17]. Patients with mutations of KISS1R exhibit hypogonadotropic hypogonadism but normal responses to $\mathrm{GnRH}$ and no reported metabolic derangement [18-20]. It is also important to note that metabolic abnormalities have not been reported in knockout models lacking kisspeptin or its receptor [21], suggesting that perturbation in the kisspeptin system is more likely to be the effect rather than the cause of a metabolic phenotype.

In rodents, two distinct populations of kisspeptin neurons exist in the arcuate (ARC) and anterior periventricular (AVPV) nuclei, with differential functional responses [22]. Kisspeptin neurons in the ARC have been shown to respond to negative feedback by gonadal steroids, while AVPV kisspeptin neurons in the female rodent respond to positive feedback by oestrogen [22]. However, AVPV is not an anatomical area present in the human hypothalamus and no kisspeptin neurons have been demonstrated in the corresponding rostral periventricular region of the third ventricle in humans [22]. The infundibular nucleus is the human homologue of the ARC where the presence of kisspeptin neurons has been documented [23]. In the rodent data reviewed here, we will focus on the kisspeptin population in the ARC nucleus as the oestrogen-mediated positive feedback seen in the female is not of particular relevance in the context of male hypogonadism. However, it has to be borne in mind that in mRNA analyses of 
gene expression, whole hypothalami are often used rather than specific nuclei, such as the ARC or AVPV, thus potentially lowering the sensitivity and specificity of any changes detected in Kiss1 mRNA expression.

\section{Support for the Hypothesis}

\section{Oestrogen-Mediated Negative Feedback and}

Kisspeptin

Peripheral conversion of androgens to oestrogens in obese men leads to increased circulating oestrogens, which in turn suppress the hypothalamic-pituitary axis and thus the production of testosterone [24]. Serum oestrone and $17-\beta$-estradiol are elevated twofold in morbidly obese men, with the urinary excretion rates of these hormones elevated in proportion to the degree of obesity [24]. Treatment with an aromatase inhibitor (preventing conversion of testosterone to estradiol) produces a sustained normalisation of serum total testosterone in obese men with hypogonadism [25].

However, adult GnRH neurons lack oestrogen receptor- $\alpha$ (ER- $\alpha)$ and rely on signaling from other oestrogen responsive hypothalamic neurons to facilitate oestrogenmediated regulation [26]. The phenotypic identity of cells that receive input from gonadal steroids and relay this information to GnRH neurons remains unknown; however, kisspeptin neurons appear likely to play this role [27]. The hypothalamic content of Kiss1 (mRNA) increases significantly after gonadectomy and decreases with sex steroid replacement [28]. Kisspeptin neurons in sheep express ER- $\alpha$ receptors [29] and in mouse models that lack functional ER- $\alpha$ receptors, Kiss 1 mRNA expression does not change in response to estradiol treatment [30]. A minority of kisspeptin neurons express the oestrogen receptor isoform ER- $\beta$ in addition to ER- $\alpha$ [30]. In the absence of ER- $\beta$ (in knockout mouse models), the inhibitory effect of E2 on transcription of Kiss1 is enhanced [30], indicating functional roles of both ER types in the regulation of kisspeptin neurons.

\section{Leptin and Kisspeptin}

Leptin secreted from adipocytes conveys information about the body's energy stores to the brain and thus regulates a number of physiological processes, including inflammation, immune function and reproduction [31]. Humans and mice lacking leptin (ob/ob mice) or leptin receptor ( $\mathrm{db} / \mathrm{db}$ mice) develop obesity, insulin-resistant diabetes and hypogonadism [31]. In obese men, circulating androgen is inversely correlated with circulating leptin [32] and a functional resistance to leptin in human obesity has been described [33].

GnRH neurons, however, show little or no expression of Ob-R mRNA [34] and, therefore, must rely on intermediary neurons for transmission of information on leptin concentrations [34]. Kisspeptin neurons may fulfill this role, as they express leptin receptors [35]. Reversal of fasting-induced inhibition of gonadotropins by exogenous kisspeptin [36] and the ability of intracerebroventricular kisspeptin administration to correct the decrease in LH secretion seen in pubertal animals after central immunoneutralisation of endogenous leptin with antileptin antibody [37] provide further evidence for a role of kisspeptin in affecting the influence of leptin on the HPG axis.

Hypothalamic Kiss1 mRNA expression is significantly reduced in ob/ob compared to wild-type mice and are increased in ob/ob mice treated with leptin [35, 38]. Moreover, administration of leptin increases hypothalamic Kiss1 mRNA as well as LH and testosterone concentrations in hypogonadotropic diabetic male rats [38].

\section{Hyperglycaemia and Kisspeptin}

Plasma testosterone is inversely related to glycaemic control in men with T2DM. However, when compared with age- and BMI-matched men [4] as well as men with type 1 diabetes of a comparable age, men with T2DM have a higher prevalence of hypogonadism [39]. This suggests insulin resistance as well as hyperglycaemia could also play a role in the pathogenesis of hypogonadism in this setting [4]. Mice with neuron-specific deletion of insulin receptors (NIRKO mice) have increased body mass and hypogonadotropic hypogonadism, confirming that insulin sensing in the brain is required for normal activity of the HPG axis [40].

Hypothalamic Kiss 1 mRNA is decreased in streptozotocin-induced diabetic rats (a model of type 1 diabetes), and the post-orchidectomy rise in Kiss1 mRNA in these hyperglycaemic animals is severely blunted [38]. Kisspeptin administration has been shown to evoke robust LH and testosterone secretion and enhance post-gonadectomy LH concentrations in hypogonadotropic streptozotocin-induced diabetic male rats [38]. Repeated administration of kisspeptin to diabetic rats also partially rescued prostate and testis weights [41]. However, no studies have yet been carried out on Kiss1 mRNA expression in animal models of T2DM.

\section{Inflammation and Kisspeptin}

Obesity and T2DM are now well recognised to be associated with inflammation and increased oxidative 
Fig. 1. Normal physiology and the pathophysiological processes underpinning our hypothesis.

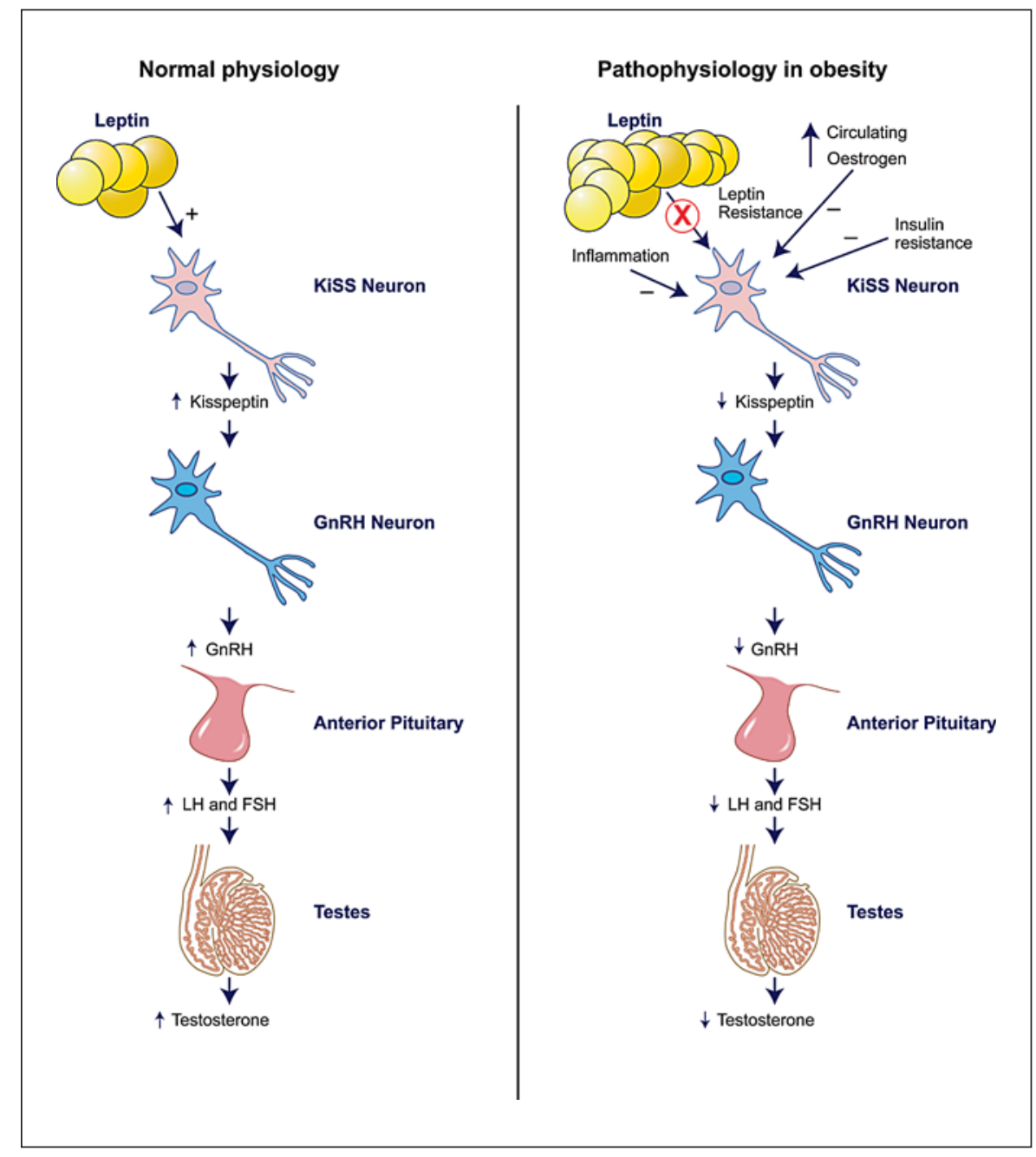

stress [42]. Circulating C-reactive protein, an inflammatory marker associated with cardiovascular risk, has been shown to be significantly higher in hypogonadal men with T2DM in comparison to men with normal plasma testosterone [4].

There are emerging data linking kisspeptin and inflammation. Administration of a pro-inflammatory agent (lipopolysaccharide) decreased hypothalamic Kiss1 mRNA expression as well as plasma LH in ovariectomised rats [43]. Indomethacin, an anti-inflammatory drug, completely blocked both these suppressive effects [43]. Whilst inflammation has long been recognised to suppress the reproductive axis (e.g. in severe or chronic illness), these early findings suggest a link between kisspeptin and inflammation.

Figure 1 summarises the normal physiology and the proposed pathophysiology underpinning our hypothesis.

\section{Testing the Hypothesis}

To test the hypothesis directly, comparison between endogenous kisspeptin secretion in obese and lean subjects would have to be made. However, the concentration of kisspeptin entering the peripheral circulation from the hypothalamus is likely to be undetectable. Accessing portal circulation via petrosal sinus sampling for sampling is technically and ethically challenging. Highly specific and sensitive assay methods to measure kisspeptins are not yet widely available $[44,45]$. Moreover, even if the technical barriers are overcome, circulatory concentrations of kisspeptin may not correlate with the intracranial milieu.

Recent advances in kisspeptin biology offer indirect alternatives to test our hypothesis. Kisspeptin neuronal hypertrophy and increased kisspeptin gene expression has been demonstrated in the hypothalamic infundibular nu- 
cleus in postmenopausal women [23]. Similar post-mortem histological analysis of hypothalami from obese men may show hypotrophy of kisspeptin neurons and/or decreased KISS1 expression. A comparable situation of hypogonadotropic hypogonadism is seen in women with hypothalamic amenorrhoea who show a significantly higher LH response to acute administration of kisspeptin-54 in comparison to healthy women in the follicular phase of menstrual cycle [46]. As hypogonadal men with metabolic syndrome have a similar gonadotropin profile to women with hypothalamic amenorrhoea, stimulatory responses in LH to exogenous kisspeptin in these men may also be increased, which if confirmed in exploratory studies, raises the possibility of using a provocative kisspeptin stimulation test as a marker of metabolic status. In recent animal studies, kisspeptin antagonists have been shown to inhibit kisspeptin-induced LH release and also block the post-gonadectomy rise in LH [47]. Moreover, in male rats with streptozocin-induced diabetes, the LH response to kisspeptin was significantly higher than control animals [48]. By analogy, increased sensitivity to kisspeptin analogues in men with hypogonadism associated with T2DM would indirectly lend support to our hypothesis. Such studies could be performed by acute stimulation with a single dose of kisspeptin, akin to the GnRH provocative test used in numerous clinical settings.

\section{Implications of the Hypothesis}

There are physiological and clinical implications if our postulates are correct.

The pathophysiology of hypogonadism in obese men remains poorly understood. Current evidence linking in- sulin, leptin, oestrogen and inflammation with hypogonadism fails to explain how these factors have effects on $\mathrm{GnRH}$ neurons which lack corresponding receptors. If our hypothesis is correct, kisspeptin will constitute the neuroendocrine link conveying information about whole body energy balance to the GnRH neuronal system.

From a translational perspective, there is potential for pharmacological therapies to be developed to address hypogonadism. A number of kisspeptin analogues are being developed with agonistic and antagonistic activities. If our hypothesis is correct, kisspeptin agonists constitute putative therapeutic targets for low circulating testosterone seen in obesity and diabetes. Current treatment of hypogonadism with testosterone tends to decrease sperm production through negative feedback on FSH secretion with resultant sub-fertility in at least some patients. Pharmacological modulation with kisspeptin agonists will potentially not have this adverse effect.

In summary, we postulate low kisspeptin secretion is part of the pathophysiology of hypogonadotropic hypogonadism seen in men with obesity and T2DM. The kisspeptin/KISS1R system is likely to be a central link between energy status and the HPG axis in man as has been demonstrated in experimental animals.

\section{Acknowledgements}

J.T.G.'s current position as a Career Development Fellow is funded by the Medical Research Council. J.T.G., R.A.A. and R.P.M. have also been awarded a project grant from Novo Nordisk UK Research Foundation for studies on pancreatic responses to kisspeptin. J.T.G. has also been awarded the Sanofi-Aventis 'Excellence in Diabetes Research Award' for studies on hypogonadism in diabetes.

\section{References}

1 Ogden CL, Yanovski SZ, Carroll MD, Flegal KM: The epidemiology of obesity. Gastroenterology 2007;132:2087-2102.

- 2 Wild S, Roglic G, Green A, Sicree R, King H: Global prevalence of diabetes: estimates for the year 2000 and projections for 2030. Diabetes Care 2004;27:1047-1053.

-3 Alberti KG, Zimmet P, Shaw J, IDF Epidemiology Task Force Consensus Group: The metabolic syndrome - a new worldwide definition. Lancet 2005;366:1059-1062.

4 Dandona P, Dhindsa S, Chaudhuri A, Bhatia V, Topiwala S, Mohanty P: Hypogonadotrophic hypogonadism in type 2 diabetes, obesity and the metabolic syndrome. Curr Mol Med 2008;8:816-828.
5 Strain GW, Zumoff B, Miller LK, et al: Effect of massive weight loss on hypothalamic-pituitary-gonadal function in obese men. J Clin Endocrinol Metab 1988;66:1019-1023.

6 Dhindsa S, Prabhakar S, Sethi M, Bandyopadhyay A, Chaudhuri A, Dandona P: Frequent occurrence of hypogonadotropic hypogonadism in type 2 diabetes. J Clin Endocrinol Metab 2004;89:5462-5468.

7 Kupelian V, Hayes FJ, Link CL, Rosen R, McKinlay JB: Inverse association of testosterone and the metabolic syndrome in men is consistent across race and ethnic groups. J Clin Endocrinol Metab 2008;93:3403-3410.
8 Kupelian V, Page ST, Araujo AB, Travison TG, Bremner WJ, McKinlay JB: Low sex hormone-binding globulin, total testosterone, and symptomatic androgen deficiency are associated with development of the metabolic syndrome in nonobese men. J Clin Endocrinol Metab 2006;91:843-850.

$\checkmark 9$ Kapoor D, Goodwin E, Channer KS, Jones $\mathrm{TH}$ : Testosterone replacement therapy improves insulin resistance, glycaemic control, visceral adiposity and hypercholesterolaemia in hypogonadal men with type 2 diabetes. Eur J Endocrinol 2006;154:899906. 
10 Malkin CJ, Pugh PJ, Morris PD, Kerry KE, Jones RD, Jones $\mathrm{TH}$, et al: Testosterone replacement in hypogonadal men with angina improves ischaemic threshold and quality of life. Heart 2004;90:871-876.

11 Hill JW, Elmquist JK, Elias CF: Hypothalamic pathways linking energy balance and reproduction. Am J Physiol Endocrinol Metab 2008;294:E827-E832.

12 Roseweir AK, Millar RP: The role of kisspeptin in the control of gonadotrophin secretion. Hum Reprod Update 2009;15:203212.

-13 Vermeulen A, Kaufman J, Deslypere J, Thomas G: Attenuated luteinizing hormone (LH) pulse amplitude but normal LH pulse frequency, and its relation to plasma androgens in hypogonadism of obese men. J Clin Endocrinol Metab 1993;76:1140-1146.

-14 Tripathy D, Dhindsa S, Garg R, Khaishagi A, Syed T, Dandona P: Hypogonadotropic hypogonadism in erectile dysfunction associated with type 2 diabetes mellitus: a common defect? Metab Syndr Relat Disord 2003;1:7580.

15 Lee J, Miele ME, Hicks DJ, et al: KiSS-1, a novel human malignant melanoma metastasis-suppressor gene. J Natl Cancer Inst 1996; 88:1731-1737.

16 Dhillo WS, Chaudhri OB, Patterson M, et al: Kisspeptin-54 stimulates the hypothalamicpituitary gonadal axis in human males. Clin Endocrinol Metab 2005;90:6609-6615.

-17 Tena-Sempere M: KiSS-1 and reproduction: focus on its role in the metabolic regulation of fertility. Neuroendocrinology 2006;83: 275-281.

18 de Roux N, Genin E, Carel J, Matsuda F, Chaussain J, Milgrom E: Hypogonadotropic hypogonadism due to loss of function of the KiSS1-derived peptide receptor GPR54. Proc Natl Acad Sci USA 2003;100:10972-10976.

19 Chan Y, Broder-Fingert S, Seminara SB: Reproductive functions of kisspeptin and Gpr54 across the life cycle of mice and men. Peptides 2009;30:42-48.

20 Seminara SB, Messager S, Chatzidaki EE, et al: The GPR54 gene as a regulator of puberty. N Engl J Med 2003;349:1614-1627.

21 Colledge WH: Transgenic mouse models to study Gpr54/kisspeptin physiology. Peptides 2009;30:34-41.

22 Oakley AE, Clifton DK, Steiner RA: Kisspeptin signaling in the brain. Endocr Rev 2009;30:713-743.

23 Rometo AM, Krajewski SJ, Lou Voytko M, Rance NE: Hypertrophy and increased kisspeptin gene expression in the hypothalamic infundibular nucleus of postmenopausal women and ovariectomized monkeys. J Clin Endocrinol Metab 2007;92:2744-2750.
Schneider G, Kirschner M, Berkowitz R, Ertel $\mathrm{N}$ : Increased estrogen production in obese men. J Clin Endocrinol Metab 1979;48: 633-638.

25 Loves S, Ruinemans-Koerts J, de Boer H: Letrozole once a week normalizes serum testosterone in obesity-related male hypogonadism. Eur J Endocrinol 2008;158:741-747.

26 Herbison AE: Multimodal influence of estrogen upon gonadotropin-releasing hormone neurons. Endocr Rev 1998;19:302330.

27 Smith JT, Clifton DK, Steiner RA: Regulation of the neuroendocrine reproductive axis by kisspeptin-GPR54 signaling. Reproduction 2006;131:623-630.

-28 Navarro VM, Castellano JM, FernándezFernández R, et al: Developmental and hormonally regulated messenger ribonucleic acid expression of KiSS-1 and its putative receptor, GPR54, in rat hypothalamus and potent luteinizing hormone-releasing activity of KiSS-1 peptide. Endocrinology 2004;145: 4565-4574.

29 Franceschini I, Lomet D, Cateau M, Delsol G, Tillet Y, Caraty A: Kisspeptin immunoreactive cells of the ovine preoptic area and arcuate nucleus co-express estrogen receptor alpha. Neurosci Lett 2006;401:225-230.

30 Smith JT, Cunningham MJ, Rissman EF, Clifton DK, Steiner RA: Regulation of Kiss1 Gene Expression in the Brain of the Female Mouse. Endocrinology 2005; 146:36863692

31 Farooqi IS, O’Rahilly S: Leptin: a pivotal regulator of human energy homeostasis. Am J Clin Nutr 2009;89:980S-984S.

32 Isidori AM, Caprio M, Strollo F, et al: Leptin and androgens in male obesity: evidence for leptin contribution to reduced androgen levels. J Clin Endocrinol Metab 1999;84:36733680.

33 Rasouli N, Kern PA: Adipocytokines and the metabolic complications of obesity. J Clin Endocrinol Metab 2008;93:S64-S73.

- 34 Finn PD, Cunningham MJ, Pau KY, Spies HG, Clifton DK, Steiner RA: The stimulatory effect of leptin on the neuroendocrine reproductive axis of the monkey. Endocrinology 1998;139:4652-4662.

35 Smith JT, Acohido BV, Clifton DK, Steiner RA: KiSS-1 neurones are direct targets for leptin in the ob/ob mouse. J Neuroendocrinol 2006;18:298-303.

36 Castellano JM, Navarro VM, FernándezFernández R, et al: Changes in hypothalamic KiSS-1 system and restoration of pubertal activation of the reproductive axis by kisspeptin in undernutrition. Endocrinology 2005;146:3917-3925.
37 Navarro VM, Fernández-Fernández R, Castellano JM, et al: Advanced vaginal opening and precocious activation of the reproductive axis by KiSS-1 peptide, the endogenous ligand of GPR54. J Physiol 2004;561:379386.

38 Castellano JM, Navarro VM, FernándezFernández R, et al: Expression of hypothalamic KiSS-1 system and rescue of defective gonadotropic responses by kisspeptin in streptozotocin-induced diabetic male rats. Diabetes 2006;55:2602-2610.

39 Chandel A, Dhindsa S, Topiwala S, Chaudhuri A, Dandona P: Testosterone concentration in young patients with diabetes. Diabetes Care 2008;31:2013-2017.

40 Bruning JC, Gautam D, Burks DJ, et al: Role of brain insulin receptor in control of body weight and reproduction. Science 2000;289: 2122-2125.

-41 Castellano JM, Roa J, Luque RM, Dieguez C, Aguilar E, Pinilla L, et al: KiSS-1/kisspeptins and the metabolic control of reproduction: physiologic roles and putative physiopathological implications. Peptides 2009;30:139145 .

42 Sattar N, Perry CG, Petrie JR: Type 2 diabetes as an inflammatory disorder. Br J Diabetes Vasc Dis 2003;3:36-41.

43 Iwasa T, Matsuzaki T, Murakami M, et al: Decreased expression of kisspeptin mediates acute immune/inflammatory stress-induced suppression of gonadotropin secretion in $\mathrm{fe}$ male rat. J Endocrinol Invest 2008;31:656659.

-44 Horikoshi Y, Matsumoto H, Takatsu Y, et al: Dramatic elevation of plasma metastin concentrations in human pregnancy: metastin as a novel placenta-derived hormone in humans. J Clin Endocrinol Metab 2003;88:914919.

45 Ramachandran R, Patterson M, Murphy KG et al: Preanalytical factors affecting RIA measurement of plasma kisspeptin. Clin Chem 2008;54:615-617.

46 Jayasena CN, Nijher GMK, Chaudhri OB, et al: Subcutaneous injection of kisspeptin-54 acutely stimulates gonadotropin secretion in women with hypothalamic amenorrhea, but chronic administration causes tachyphylaxis. J Clin Endocrinol Metab 2009;94:43154323.

-47 Roseweir AK, Kauffman AS, Smith JT, et al: Discovery of potent kisspeptin antagonists delineate physiological mechanisms of gonadotropin regulation. J Neurosci 2009;29: 3920-3929.

48 Castellano JM, Navarro VM, Roa J, et al: Alterations in hypothalamic KiSS-1 system in experimental diabetes: early changes and functional consequences. Endocrinology 2009;150:784-794 